\title{
Volatile Organic Compounds Emanating from Indoor Ornamental Plants
}

\author{
Dong Sik Yang \\ Department of Horticultural Science, The University of Georgia, Athens, \\ GA 30602-7273
}

\section{Ki-Cheol Son \\ Department of Environmental Science, Konkuk University, Seoul 143-701, Korea}

\author{
Stanley J. Kays ${ }^{1}$ \\ Department of Horticulture, The Plant Center, 1111 Plant Sciences Building, \\ The University of Georgia, Athens, GA 30602-7273
}

Additional index words. air quality, Chrysalidocarpus lutescens, Ficus benjamina, Sansevieria trifasciata, Spathiphyllum wallisii, dynamic headspace, Tenax TA

\begin{abstract}
A broad cross-section of volatiles emanating from four species of popular indoor ornamental plants (Spathiphyllum wallisii Regel, Sansevieria trifasciata Prain, Ficus benjamina L., and Chrysalidocarpus lutescens Wendl.) was identified and categorized based on source. Volatile organic compounds from individual plants were obtained using a dynamic headspace system and trapped on Tenax TA during the day and again at night. Using short-path thermal desorption and cryofocusing, the volatiles were transferred onto a capillary column and analyzed using gas chromatography-mass spectroscopy. The volatiles originated from the plants, media/micro-organisms, pot, and pesticides. A total of $23,12,13$, and 16 compounds were identified from $S$. wallisii, $S$. trifasciata, $F$. benjamina, and $C$. lutescens, respectively. The night emanation rate was substantially reduced (i.e., by $30.1 \%, 69.5 \%, 73.7 \%$, and $63.1 \%$, respectively) reflecting in part the regulation of biosynthesis and the greater diffusion resistance when the stomata were closed. $S$. wallisii had the highest emanation rate, releasing 15 terpenoid compounds [e.g., linaloloxide, linalool, $(Z)-\beta$-farnesene, farnesal, $(+)$ - $\delta$-cadinene, $(+)$ $\beta$-costol] into the surrounding air. Alpha-farnesene $(90.3 \%)$ was quantitatively the dominant volatile present followed by $(Z)-\beta$-farnesene $(1.4 \%),(+)-\beta$-costol $(1.4 \%)$, and farnesal (1.1\%). Substantially fewer terpenoids (i.e., two, nine, and eight) emanated from $S$. trifasciata, $F$. benjamina, and $C$. lutescens, which quantitatively emitted fewer volatiles than $S$. wallisii. Most terpenoids from the four species were sesquiterpenes rather than monoterpenes. Methyl salicylate, a plant-signaling compound, was emitted by all four species. Certain volatiles (e.g., 2-chlorobenzonitrile, 1-ethyl-3,5-dimethylbenzene) were released from growth media and/or micro-organisms therein; other sources included the plastic pot (e.g., 2-ethyl-1-hexanol, octamethyl cyclotetrasiloxane) and pesticide ingredients [e.g., 2-(2-methoxy- ethoxy)ethanol, 2-ethylhexyl salicylate, homosalate].
\end{abstract}

The use of ornamental plants in interiorscapes is increasingly being studied for their ability to remove volatile organic compounds, thereby improving the air quality of indoor environments (Kim et al., 2008; Yoo et al., 2006). Deterioration of indoor air quality can result in "multiple chemical sensitivity," "new house syndrome," and "sick building syndrome" and a cross-section of adverse physical symptoms for those exposed (e.g., allergies, frequent fatigue, asthma, headache, a feeling of uneasiness) (Jones, 1999; Kostiainen, 1995). 2-Ethyl-1-hexanol, formaldehyde, and benzene are common indoor pollutants that are detrimental to health and are emitted from a cross-section of materials found inside

Received for publication 24 June 2008. Accepted for publication 29 July 2008.

${ }^{1}$ To whom reprint requests should be addressed; e-mail kaysstan@uga.edu. [e.g., attraction of pollinators, protection against pathogens or herbivories, enhanced thermotolerance (Dudareva et al., 2004; Pichersky et al., 2006)]. A cross-section of plant-derived volatiles also plays important roles in scent and flavor. For example, volatile compounds (e.g., 2- and 3-methylbutanal, 3-methylbutanol, phenyl acetaldehyde, 2phenylethanol, methyl salicylate) derived from amino acids in tomato play an important role in characterizing tomato flavor (Goff and Klee, 2006). Several terpenoid compounds [e.g., camphene, $p$-cymene, $\delta$-3-carene, $\alpha$ humulene, limonene, linalool, $(E)$ - $\beta$-ocimene, $\alpha$-pinene, $\beta$-thujone] contribute to the fragrance of Heliotropium arborescens (Kays et al., 2005). In addition, volatiles synthesized in some plants have specific health properties: curcumin in turmeric (antiinflammatory and antitumor activities); curcumene, gingerol, and gingerone in ginger (antioxidant and antitumor activities); and camphor and methyl cinnamate in galangal (antimicrobial activity) (Goff and Klee, 2006). Although significant advances have been made in the identification of critical odorants, much less is known about volatiles that have little or no odor and on the dynamics of the interaction between indoor plants and air quality.

The objective of this study was to identify and quantify volatiles emanating from four popular potted indoor ornamental species, establish the source of the volatiles, and determine if the rate of emanation differed between day and night.

\section{Materials and Methods}

Plant material and collection of volatiles. Four potted indoor ornamental plant species were purchased from a commercial market (Spathiphyllum wallisii Regel, Sansevieria trifasciata Prain, Ficus benjamina L., and Chrysalidocarpus lutescens Wendl.) and acclimatized for 2 weeks to indoor conditions, i.e., $25 \pm 1{ }^{\circ} \mathrm{C}, 50 \%$ relative humidity, and $5.45 \mu \mathrm{mol} \cdot \mathrm{m}^{-2} \cdot \mathrm{s}^{-1}$ photosynthetically active radiation. $S$. wallisii was in flower during the test period. The dry weights of the aerial part in $S$. wallisii, S. trifasciata, $F$. benjamina, and C. lutescens were 16.7, 61.4, 43.1, and $34.3 \mathrm{~g}$, respectively. Individual plants planted in 15 -cm-diameter pots were placed in a meticulously cleaned 39-L glass container with inlet and outlet ports. The inlet port was connected to a charcoal filter (Alltech Assoc. Inc., Deerfield, IL) [Pyrex glass tube $(10 \mathrm{~cm} \times 1 \mathrm{~cm}$ i.d.) with $7 \mathrm{~cm}$ of $2.5 \mathrm{~g}$ of charcoal] to supply purified air and the outlet port was connected to a sorbent trap $(10 \mathrm{~cm}$ long, $6 \mathrm{~mm}$ o.d., $4 \mathrm{~mm}$ i.d. stainless steel sorbent trap; Scientific Instrument Services, Inc., Ringoes, NJ) containing $150 \mathrm{mg}$ of 60 / 80 mesh Tenax-TA ${ }^{\circledR}$ (Alltech Assoc. Inc.) followed by a portable air sampling pump (LFS-113DC; Sensidyne Inc., Clearwater, FL). Volatile compounds emanating from the plant were collected for $10 \mathrm{~h}$ by flowing purified air into the container at $20 \mathrm{~mL} / \mathrm{min}$. Samples were also collected from empty 
chambers to verify the absence of contaminants. Samples were collected during both the day and night (12-h photoperiod). The rates of emanation for the individual volatiles are relative and do not represent absolute amounts. Collection began $2 \mathrm{~h}$ after the plant was placed in the container. Volatiles from the plastic pot with the media and the plastic pot alone were similarly assessed to determine the source of the individual compounds, i.e., plant, media/micro-organisms, and pot.

Short-path thermal desorption. An automated short path thermal desorption system (TD-5; Scientific Instrument Services) mounted on the injection port of the gas chromatograph-mass spectrometer (GCMS) (6890N/5973; Agilent, Palo Alto, CA) desorbed the volatiles from the Tenax trap at $250{ }^{\circ} \mathrm{C}$ for $5 \mathrm{~min}$. The volatiles were collected on the first $4 \mathrm{~cm}$ of the capillary column using a cryofocus trap (SIS 2" Cryo-Trap; Scientific Instrument Services) cooling to $-40{ }^{\circ} \mathrm{C}$ with liquid $\mathrm{CO}_{2}$, and subsequently released by rapidly heating the trap to $200^{\circ} \mathrm{C}$.

Separation, identification, and quantification of volatiles. Volatiles were identified and quantified using a GC-MS equipped with a 30 -m length $\times 0.25$-mm i.d., $0.25-\mu \mathrm{m}$ film thickness of $5 \%$ phenyl methyl siloxane, fused silica capillary column (HP-5MS; Agilent). The injection port temperature was 225 ${ }^{\circ} \mathrm{C}$ with a split ratio of $5: 1$. Helium was used as the carrier gas at a flow rate of $1.0 \mathrm{~mL} / \mathrm{min}$. The column temperature was held at $40{ }^{\circ} \mathrm{C}$ for $1 \mathrm{~min}$ and then programmed $5{ }^{\circ} \mathrm{C} / \mathrm{min}$ to $280{ }^{\circ} \mathrm{C}$ and held for $5 \mathrm{~min}$. MS conditions were: ion source $230{ }^{\circ} \mathrm{C}$, electron energy 70 $\mathrm{eV}$, multiplier voltage $1247 \mathrm{~V}$, GC-MS interface zone $280{ }^{\circ} \mathrm{C}$, and a scan range of 35 to 350 mass units. The volatiles were identified based on comparison of their mass spectra and relative abundances with NIST 02 and Wiley 7 spectral libraries. The concentrations of individual volatiles were expressed as $\delta$ carvone equivalents and are considered relative because recovery and calibration factors were not determined. The internal standard was introduced by placing $5 \mathrm{~mL}$ of $\delta$-carvone in a sealed 1-L Erlenmeyer flask. After $24 \mathrm{~h}$, $50 \mathrm{~mL}$ of air saturated with $\delta$-carvone was removed and injected into the glass container holding the test plant at the beginning of volatile collection. The concentration of the internal standard in the trapped sample was determined using a concentration range of authentic standards in hexane directly injected into the GC.

\section{Results and Discussion}

Volatile organic compounds emanating from individual plants. A total of 23, 12, 13, and 16 volatile organic compounds were identified from $S$. wallisii, $S$. trifasciata, $F$. benjamina, and $C$. lutescens, respectively (Table 1). The volatiles were comprised of terpenoids, alcohols, ketones, and esters (Fig. 1 ). Based on the relative proportion of the primary classes, terpenoids were quantitatively dominant in $S$. wallisii $(97.8 \%), F$. benjamina $(79.0 \%)$, and C. lutescens $(66.9 \%)$; however, esters $(34.6 \%)$ were quantitatively dominant in $S$. trifasciata followed by ketones $(26.9 \%)$, alcohols $(26.6 \%)$, and terpenoids $(11.9 \%)$. Certain compounds were found in all four species, i.e., butyl butyrate, methyl salicylate, and isopropyl myristate.

The phenolic compound methyl salicylate, known to emanate from a number of species, comprised $0.2 \%, 17.8 \%, 7.8 \%$, and

Table 1. Relative concentration of volatile organic compounds emanating from four species of indoor ornamental plants (Spathiphyllum wallisii, Sansevieria trifasciata, Ficus benjamina, and Chrysalidocarpus lutescens) during the day and night.

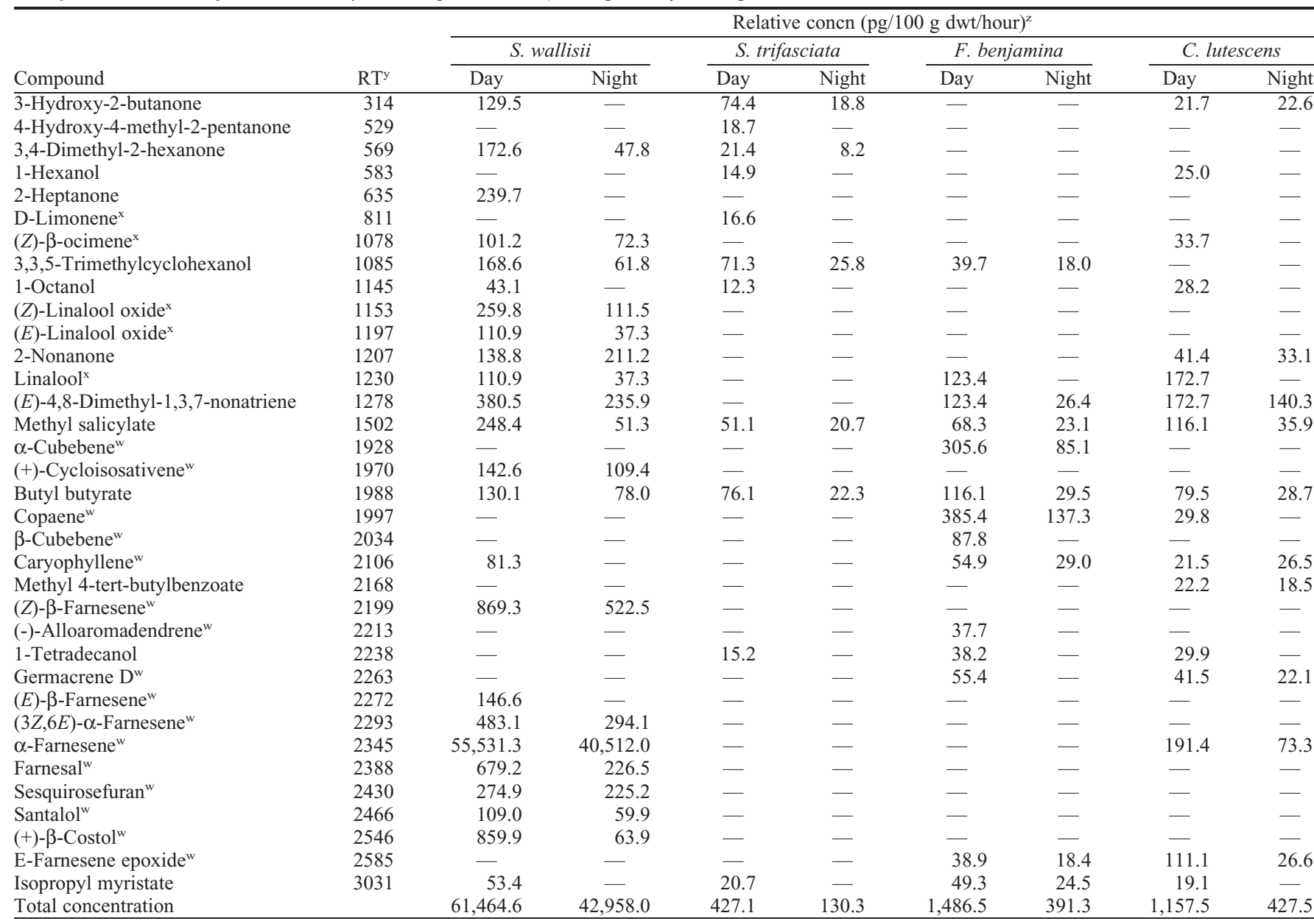

${ }^{2}$ Values expressed as $\delta$-carvone equivalent.

${ }^{\mathrm{y}}$ Retention time ( $\left.\mathrm{min}\right)$.

${ }^{\mathrm{x}}$ Monoterpene.

${ }^{\mathrm{w}}$ Sesqueterpene. 


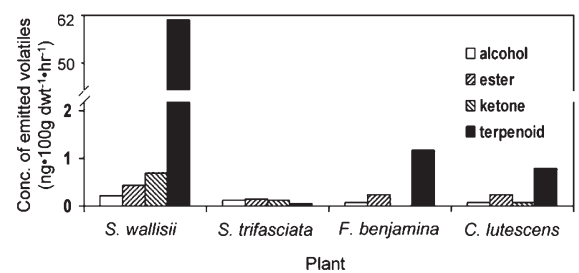

Fig. 1. The concentration of the primary classes of volatile compounds emitted by four species of plants during the day (Spathiphyllum wallisii, Sansevieria trifasciata, Ficus benjamina, and Chrysalidocarpus lutescens).

$6.9 \%$ in the volatiles of $S$. wallisii, S. trifasciata, F. benjamina, and C. lutescens, respectively. The compound acts in signal transduction and plant defense; it activates resistance in the healthy tissues of damaged and neighboring plants against pathogens. Methyl salicylate is also thought to attract predators of certain herbivores (Holopainen, 2004). Many of the volatile compounds emanating from the test species differed. There was a wide range of terpenoid compounds (Table 1), some of which have been implicated in survival and quality attributes (e.g., flavor, fragrance) or noted for their pharmacological properties (e.g., anticarcinogenic, antimicrobiological) and ecological significance (e.g., pollinator attraction, defense) (Aharoni et al., 2005).

The specific terpene synthesized varied among species (Owen and Peñuelas, 2005). Fifteen terpenoids were identified from $S$. wallisii of which four were monoterpenes [e.g., (Z)- $\beta$-ocimene, $(Z)$-linalool oxide, $(E)$ linalool oxide, linalool], 10 sesquiterpenes [e.g., $\alpha$-farnesene, $(Z)$ - $\beta$-farnesene, farnesal, $(3 Z, 6 E)$ - $\alpha$-farnesene, $(E)$ - $\beta$-farnesene, $(+)-\beta$ costol, sesquirosefuran, $(+)$-cycloisosativene, santalol, caryophyllene], and one homoterpene (e.g., (E)-4,8-dimethyl-1,3,7-nonatriene] (Table 1). Alpha-farnesene (90.3\%) was quantitatively the dominant volatile present followed by (Z)- $\beta$-farnesene (1.4\%), (+)$\beta$-costol (1.4\%), and farnesal (1.1\%). Alphafarnesene, a component of the surface coating of apple, is known to be induced in plants damaged by herbivores (Holopainen, 2004). An oxygenated product (farnesal) and isomers thereof [i.e., $(Z)$ - $\beta$-farnesene, $(E)-\beta$ farnesene, and $(3 Z, 6 E)-\alpha$-farnesene], present in $S$. wallisii (Table 1), are known to function as insect pheremones as does $\alpha$-farnesene (Dawson et al., 1982). Santalol, present in $S$. wallisii, has been reported to have a relaxing and sedative effect in humans (Hongratanaworakit et al., 2004). Several monoterpenes identified in $S$. wallisii have been reported as major compounds in a variety of species, e.g., linalool in lavender and jasmine tea (Baser et al., 2005; Ito et al., 2002), linalool, and its derivatives $[(Z)$-linalool oxide and $(E)$-linalool oxide] in carnation flowers (Lavy et al., 2002). Linalool is known to have a sedative effect on autonomic nerve activity and mood and antifungal activity (D'Auria et al., 2005). Substantially fewer terpenoids (i.e., two, eight, and eight) emanated from $S$. trifasciata, F. benjamina, and C. lutescens, which were not in flower and quantitatively emitted fewer volatiles than $S$. wallisii. Germacrene $\mathrm{D}$ and $E$-farnesene epoxide were found only in $F$. benjamina and $C$. lutescens; $\alpha$-cubebene, $\beta$-cubebene, and (-)-alloaromadendrene in $F$. benjamina; and limonene in $S$. trifasciata.

Most terpenoids from the four species were sesquiterpenes rather than monoterpenes. Generally, monoterpenes are synthesized in the plastids by way of the methylerythritol phosphate (MEP) pathway, whereas sesquiterpenes are synthesized in the cytosol through the mevalonate (MVA) pathway (Schwab et al., 2008). Mono- and sesquiterpenes are generally sequestered in specialized structures such as ducts or glandular storage cavities and their emanation appears to be developmentally regulated (Holopainen, 2004). For example, in $S$. wallisii, the number of terpenes increased markedly on flowering (data not shown). Therefore, variation in the biosynthesis and emission of monoterpenes and sesquiterpenes depends on the species and developmental stage. In addition to the mono- and sesquiterpenes, a $\mathrm{C}_{11}$ homoterpene $[(E)-4,8$ dimethyl-1,3,7-nonatriene] was emitted from $S$. wallisii, $F$. benjamina, and $C$. lutescens. It has been shown to be synthesized in response to herbivore (maize) and ozone damage (lima bean), acting as a predator attractant and in defense against phytotoxic ozone, respectively (Vuorinen et al., 2004). Blending $(E)$-4,8-dimethyl-1,3,7-nonatriene with $(E)$ $\beta$-farnesene and $\beta$-caryophyllene attracts

Table 2. Relative concentration of volatile organic compounds emanating from the media/micro-organisms, plastic pot, and pesticides of four species of potted indoor ornamental plants (Spathiphyllum wallisii, Sansevieria trifasciata, Ficus benjamina, and Chrysalidocarpus lutescens).

\begin{tabular}{|c|c|c|c|c|c|c|}
\hline \multirow[b]{2}{*}{ Source } & \multirow[b]{2}{*}{ Compound } & \multirow[b]{2}{*}{$\mathrm{RT}^{\mathrm{y}}$} & \multicolumn{4}{|c|}{ Relative concn (pg/potted plant/hour) ${ }^{\mathrm{z}}$} \\
\hline & & & S. wallisii & S. trifasciata & F. benjamina & C. lutescens \\
\hline \multirow{12}{*}{$\begin{array}{l}\text { Micro-organisms } \\
\quad+\text { media }\end{array}$} & Cyclohexanol & 623 & 33.7 & - & - & 8.3 \\
\hline & 2-Ethyl-1-pentanol & 747 & - & - & - & 34.0 \\
\hline & Heptanol & 853 & 8.9 & 7.5 & 10.8 & 12.8 \\
\hline & 2-Chlorobenzonitrile & 1431 & 53.3 & 63.6 & 76.3 & 77.0 \\
\hline & $(E)-2$-Decenal & 1689 & - & 7.5 & - & - \\
\hline & 2,4,6-Trimethyloctane & 1762 & - & 9.2 & - & - \\
\hline & 2-Undecanone & 1777 & 19.5 & 10.6 & - & 9.7 \\
\hline & 2-Ethyl-2-methyltridecanol & 1798 & - & 8.0 & - & - \\
\hline & 2,3-Dihydro-4-propyl-1H-indene & 1867 & 10.2 & - & - & - \\
\hline & 2-Undecenal & 1961 & - & 7.9 & - & - \\
\hline & Tetradecyloxirane & 2328 & - & 8.7 & 20.4 & - \\
\hline & 1-Ethyl-3,5-dimethylbenzene & 2866 & 29.5 & - & - & - \\
\hline Total concentration (pg/potted plant/hour) & & & 155.1 & 123 & 107.5 & 141.8 \\
\hline \multirow[t]{11}{*}{ Plastic pot } & Hexamethylcyclotrisiloxane & 474 & 150.1 & 161.8 & 199.2 & 94.4 \\
\hline & Octamethylcyclotetrasiloxane & 942 & 556.5 & 444.1 & 297.5 & 317.3 \\
\hline & 1-(2-Methoxypropoxy)-2-propanol & 988 & 58.5 & 48.3 & 25.1 & 16.4 \\
\hline & 2-Ethyl-1-hexanol & 1022 & 101.8 & 45.3 & 57.4 & 180.0 \\
\hline & 4-Ethyldecane & 1105 & 19.0 & 29.7 & 22.5 & 17.9 \\
\hline & 3,7-Dimethyldecane & 1236 & 7.0 & 8.6 & 8.0 & 6.3 \\
\hline & 2,4-Bis(trimethylsiloxy)benzaldehyde & 1398 & 76.0 & 61.3 & 129.0 & 54.5 \\
\hline & 8-Methylheptadecane & 1739 & 31.8 & 61.2 & 35.7 & 29.6 \\
\hline & 2,6,11-Trimethyldodecane & 1862 & 19.1 & 36.4 & 31.6 & 21.8 \\
\hline & 2,6-Di-tert-butylquinone & 2225 & 20.7 & 24.9 & 17.1 & 18.9 \\
\hline & 5,9,13-Trimethyl-4,8,12-tetradecatrienal & 3059 & 8.2 & 10.6 & 12.0 & 18.7 \\
\hline Total concentration (pg/potted plant/hour) & & & 1048.7 & 932.2 & 835.1 & 775.8 \\
\hline \multirow[t]{3}{*}{ Pesticides } & 2-(2-Methoxyethoxy)ethanol & 768 & 9.3 & 262.9 & 28.5 & 20.5 \\
\hline & 2-Ethylhexylsalicylate & 2993 & 9.4 & 8.8 & 16.8 & 10.1 \\
\hline & Homosalate & 3155 & 5.2 & 5.0 & 17.8 & 5.6 \\
\hline Total concentration (pg/potted plant/hour) & & & 23.9 & 276.7 & 63.1 & 36.2 \\
\hline
\end{tabular}

${ }^{\mathrm{z}}$ Values expressed as $\delta$-carvone equivalent

${ }^{\mathrm{y}}$ Retention time $(\mathrm{min})$. 
grapevine moth females for egg laying on flower buds through an antennal response (Tasin et al., 2007).

Volatile organic compounds emanating from micro-organisms/media and plastic pot. Certain volatiles [e.g., cyclohexanol, 2ethyl-1-pentanol, heptanol, 2-chlorobenzonitrile, $(E)$-2-decenal, 2,4,6-trimethyloctane, 2-undecanone, 2-ethyl-2-methyltridecanol, 2,3-dihydro-4- propyl-1H-indene, 2-undecenal, tetradecyloxirane, 1-ethyl-3,5-dimethylbenzene] emanated from the growing media or micro-organisms therein (Table 2). Although micro-organisms in the media have been shown to be important in the removal of volatile air pollutants, they also release volatiles into the atmosphere, some of which are biologically active. For example, 2- chlorobenzonitrile has been shown to stimulate root formation in bean seedlings and 1-ethyl-3,5dimethylbenzene is considered an allelopathic substance found in rice root exudate (Kim and Kim, 2000). Therefore, the media/ micro-organisms are not only involved in removing indoor pollutants, but also release volatiles into the air.

Eleven volatile compounds originated from the plastic pots (Table 2). The silicone compounds hexamethyl cyclotrisiloxane, octamethyl cyclotetrasiloxane, and 2,4-bis (trimethylsiloxy) benzaldehyde were quantitatively the most abundant emitted. Several of the compounds are known to have undesirable effects on animals. For example, lowlevel octamethyl cyclotetrasiloxane exposure has been shown to cause altered immune responses in animals. One of the compounds, 2-ethyl-1-hexanol in the 2 to $32 \mu \mathrm{g} \cdot \mathrm{m}^{-3}$ concentration range, is associated with "sick building syndrome," which can cause asthma in humans (Norbäck et al., 2000). 2-(2Methoxyethoxy)ethanol, 2-ethylhexyl salicylate, and homosalate are ingredients of pesticides that were apparently applied to several of the species during the production phase.

Difference in emission between day and night. The volatiles from individual plants were collected for $10 \mathrm{~h}$ during the day and again
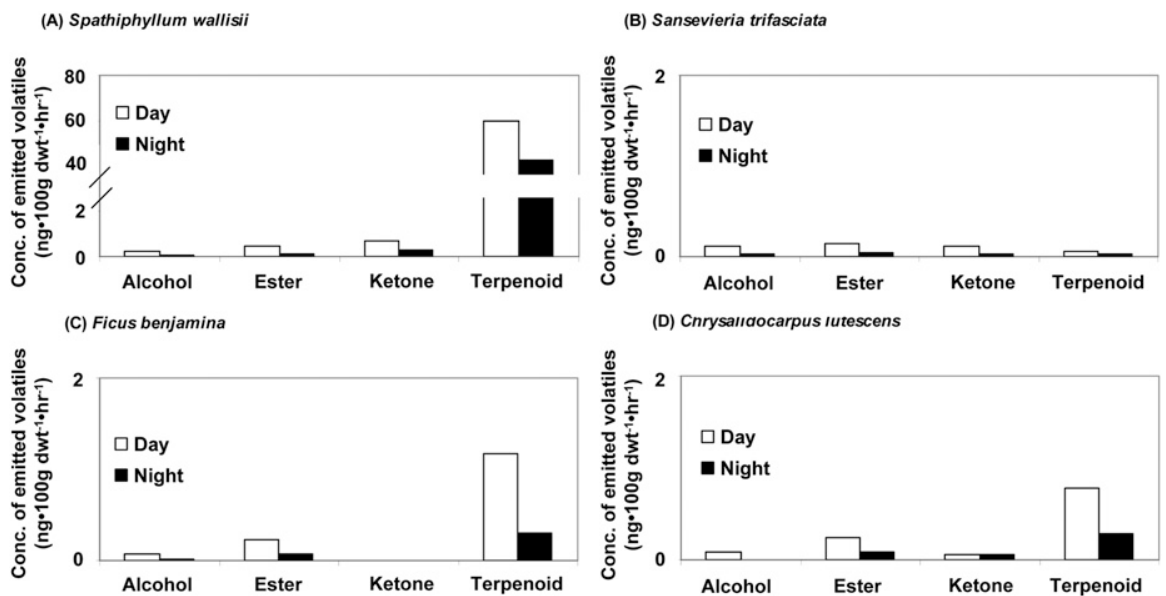

Fig. 2. Comparison of the concentration of the primary classes of volatile compounds emitted by four species of plants during the day and night.

at night. The total amounts during the day were $61.5,0.4,1.5$, and $1.2 \mathrm{ng} \cdot 100 \mathrm{~g}^{-1} \mathrm{dw} /$ hour from $S$. wallisii, S. trifasciata, F. benjamina, and $C$. lutescens, respectively. At night, the volatile emission rate was substantially reduced (e.g., by $30.1 \%, 69.5 \%$, $73.7 \%$, and $63.1 \%$, respectively) and the total number of volatiles was also reduced to five, seven, four, and six, respectively (Table 1; Fig. 2). In addition to the total amounts, all classes (i.e., alcohols, esters, ketones, and terpenoids) were substantially higher during the day for each of the species (Table 1; Fig. 2). Past research has found that rose flowers also emitted a greater amount of two terpenoid compounds (germacrene D and geranyl acetate) during the first $3 \mathrm{~h}$ of the light period (Hendel-Rahmanim et al., 2007). Plant volatile emissions are regulated by their rate of synthesis and release (Dudareva et al., 2004). The biosynthesis of volatile compounds in the epidermal cells of plant tissues, secretory structures, and glandular trichomes depends on multiple biochemical pathways [e.g., terpenoids by MVA and MEP pathways; volatile fatty acid derivatives (e.g., alcohols, ketones, esters) by $\alpha$-oxidation, $\beta$-oxidation, and lipoxygenase pathways] involving a number enzymes (Schwab et al., 2008). Emanation is affected by the physical properties of the individual compounds and the characteristics of their site of accumulation (e.g., cellular and intracellular membranes, secretory compartment) (Dudareva et al., 2004). The rate of biosynthesis and release is greatly influenced by abiotic factors such as light (Dudareva et al., 2004; Sharkey and Yeh, 2001). Light decreases the diffusion resistance of stomata during the day and the availability of glyceraldehyde-3-phosphate, a precursor of terpenes formed during photosynthesis (Niinemets et al., 2004). There are a number of reports indicating the effect of light on monoterpene synthesis and emission (Kesselmeier and Staudt, 1999; Logan et al., 2000; Loreto et al., 1996; Staudt and Bertin, 1998; Yokouchi and Ambe, 1984).

Although indoor ornamental plants have been shown to remove certain volatile air

HortScience Vol. 44(2) April 2009 pollutants from the air (Yoo et al., 2006), they also emit a diverse cross-section of compounds, some of which are known to be biologically active. The longevity and fate of these compounds have not been adequately studied. Also, the positive or negative impact of these compounds on humans balanced with the ability of plants to remove other volatile organic compounds is unknown.

\section{Literature Cited}

Aharoni, A., M.A. Jongsma, and H.J. Bouwmeester. 2005. Volatile science? Metabolic engineering of terpenoids in plants. Trends Plant Sci. 10:594-602.

Baser K.H.C., T. Ozek, and A. Konakchiev. 2005 Enantiomeric distribution of linalool, linalyl acetate and camphor in Bulgarian lavender oil. J. Essent. Oil Res. 17:135-136.

D’Auria, F.D., M. Tecca, V. Strippoli, G. Salvatore, L. Battinelli, and G. Mazzanti. 2005. Antifungal activity of Lavandula angustifolia essential oil against Candida albicans yeast and mycelial form. Medical Mycol. 43:391-396.

Dawson, G.W., D.C. Griffiths, J.A. Pickett, M.C. Smith, and C.M. Woodcock. 1982. Improved preparation of $(E)-\beta$-farnesene and its activity with economically important aphids. J. Chem. Ecol. 8:1111-1117.

Dudareva, N., E. Pichersky, and J. Gershenzon. 2004. Biochemistry of plant volatiles. Plant Physiol. 135:1893-1902.

Goff, S.A., and H.J. Klee. 2006. Plant volatile compounds: Sensory cues for health and nutritional value? Science 311:815-819.

Hendel-Rahmanim, K., T. Masci, A. Vainstein, and D. Weiss. 2007. Diurnal regulation of scent emission in rose flowers. Planta 226:14911499.

Holopainen, J.K. 2004. Multiple functions of inducible plant volatiles. Trends Plant Sci. 9:529-533.

Hongratanaworakit, T., E. Heuberger, and G. Buchbauer. 2004. Evaluation of the effects of East Indian sandalwood oil and alpha-santalol on humans after transdermal absorption. Planta Med. 70:3-7.

Ito, Y., A. Sugimoto, T. Kakuda, and K. Kubota. 2002. Identification of potent odorants in Chinese jasmine green tea scented with flowers of Jasminum sambac. J. Agr. Food Chem. 50:4878-4884.

Jones, A.P. 1999. Indoor air quality and health. Atmos. Environ. 33:4535-4564.

Kays, S.J., J. Hatch, and D.S. Yang. 2005. Volatile floral chemistry of Heliotropium arborescens L. 'Marine'. HortScience 40:1237-1238.

Kays, S.J., and R.E. Paull. 2004. Postharvest biology. Exon Press, Athens, GA.

Kesselmeier, J., and M. Staudt. 1999. Biogenic volatile organic compounds (VOC): An overview on emission, physiology and ecology. J. Atmos. Chem. 33:23-88.

Kim, K.J., M.J. Kil, J.S. Song, E.H. Yoo, K.C. Son and S.J. Kays. 2008. Efficiency of volatile formaldehyde removal by indoor plants: Contribution of aerial plant parts versus the rootzone. J. Amer. Soc. Hort. Sci. 133:1-6.

Kim, K.W., and K.U. Kim. 2000. Searching for rice allelochemicals, p. 83-95. In: Kim, K.U. and D.H. Shin (eds.). Rice allelopathy. Kyungpook National Univ. Press, Daegu, Korea.

Kostiainen, R. 1995. Volatile organic compounds in the indoor air of normal and sick houses. Atmos. Environ. 29:693-702.

Lavy, M., A. Zuker, E. Lewinsohn, O. Larkov, U. Ravid, A. Vainstein, and D. Weiss. 2002. 
Linalool and linalool oxide production in transgenic carnation flowers expressing the Clarkia breweri linalool synthase gene. Mol. Breed. 9:103-111.

Logan, B.A., R.K. Monson, and M.J. Potosnak. 2000. Biochemistry and physiology of foliar isoprene production. Trends Plant Sci. 5:477481.

Loreto, F., P. Ciccioli, A. Cecinato, E. Brancaleoni, M. Frattoni, C. Fabozzi, and D. Tricoli. 1996. Evidence of the photosynthetic origin of monoterpenes emitted by Quercus ilex L. leaves by ${ }^{13} \mathrm{C}$ labeling. Plant Physiol. 110:1317-1322.

Niinemets, Ü., F. Loreto, and M. Reichstein. 2004. Physiological and physicochemical controls on foliar volatile organic compound emissions. Trends Plant Sci. 9:180-186.

Norbäck, D., G. Wieslander, K. Nordström, and R. Wålinder. 2000. Asthma symptoms in relation to measured building dampness in upper concrete floor construction, and 2-ethyl-1-hexanol in indoor air. Intl. J. Tuberc. Lung Dis. 4:10161025.

Orwell, R.L., R.L. Wood, J. Tarran, F. Torpy, and M.D. Burchett. 2004. Removal of benzene by the indoor plant/substrate microcosm and implications for air quality. Water Air Soil Pollution 157:193-207.

Owen, S.M., and J. Peñuelas. 2005. Opportunistic emissions of volatile isoprenoids. Trends Plant Sci. 10:420-426.

Pichersky, E., J.P. Noel, and N. Dudareva. 2006. Biosynthesis of plant volatiles: Nature's diversity and ingenuity. Science 311:808-811.

Schwab, W., R. Davidovich-Rikanati, and E. Lewinsohn. 2008. Biosynthesis of plant-derived flavor compounds. Plant J. 54:712-732.

Sharkey, T.D., and S. Yeh. 2001. Isoprene emission from plants. Ann. Rev. Plant Physiol. Plant Mol. Biol. 52:407-436.

Staudt, M., and N. Bertin. 1998. Light and temperature on the emission of cyclic and acyclic monoterpenes from holm oak (Quercus ilex L.) leaves. Plant, Cell and Environ. 21:385-395.

Tasin, M., A. Bäckman, M. Coracini, D. Casado, C. Ioriatti, and P. Witzgall. 2007. Synergism and redundancy in a plant volatile blend attracting grapevine moth females. Phytochemistry 68:203-209.

Vuorinen, T., A.M. Nerg, and J.K. Holopainen. 2004. Ozone exposure triggers the emission of herbivore-induced plant volatiles, but does not disturb tritrophic signaling. Environ. Pollut. 131:305-311.

Yokouchi, Y., and Y. Ambe. 1984. Factors affecting the emission of monoterpenes from red pine (Pinus densiflora). Plant Physiol. 75:10091012.

Yoo, M.H., Y.J. Kwon, K.C. Son, and S.J. Kays, 2006. Efficacy of indoor plants for the removal of single and mixed volatile organic pollutants and physiological effects of the volatiles on the plants. J. Amer. Soc. Hort. Sci. 131:452-458. 